SUS-RURI: Proceedings of a Workshop on Developing a Convergence Sustainable Urban Systems Agenda for Redesigning the Urban-Rural Interface along the Mississippi River Watershed held in Ames, lowa, August 12-13, 2019

\title{
Water Literacy:
}

Transdisciplinary Methods

for Strengthening K-12

Science Education

Claire Anderson ${ }^{1}$, Laura Koo Nicholas ${ }^{1}$

${ }^{1}$ Ripple Effect

Published on: Jan 09, 2020

DOI: $10.31274 / 3 d 9 e a 6 a 4.9 d d f 8 c 7 b$

License: Creative Commons Attribution 4.0 International License (CC-BY 4.0). 


\section{Overview}

We understand the field of Sustainable Urban Systems to be one way in which academia is helping human society respond systematically to a rapidly changing climate and world. Kindergarten-12th grade (K-12) formal education is one component of urban systems, and it, too, is facing its own set of systemic challenges. Our organization's primary focus is on the disconnect between the new science standards and individual teachers. We believe repairing that disconnect requires a transdisciplinary, or possibly a convergent, effort. Through a shared vision of water literacy, Ripple Effect hopes to create a coherent whole out of the scattered teachers working individually, so that as a community they can function as and benefit from being an organization that learns. We believe teachers will be better equipped to respond proportionately to the changes facing them and pass those benefits on to their students.

\section{Context}

Here in the Gulf South, where the Mississippi River meets the Gulf of Mexico, the impacts of climate change pose a near-daily existential threat that worsens with each passing year. Sea-level rise, subsidence, erosion, and wetland loss occur more quickly here than anywhere else in the United States. A recent conservative estimate predicts that over the next fifty years, assuming 1.41 feet of sea-level rise, 1,250 square miles of coastal Louisiana could be lost if no additional action is taken to preserve or create new land. In an aggressive scenario, as much as 4,123 square miles could be lost. 1

The residents of this region are first-hand witnesses to these rapidly changing environments. In a single generation, they have seen centuries-old wetlands transition permanently to open water. They know and have visited towns and communities that have been erased from the map entirely or are in the process of disappearing. They have noted an increase in the frequency and severity of major storms. Louisianians, in particular, face water threats on multiple fronts: the Gulf, storm surge, the River and bayous, and the sky. Cities in the region are pursuing resilience and adaptation plans, which call for a paradigm shift from "control of nature" toward "living with water. ${ }^{\mathrm{TM}}$ " $\underline{2}$ Meanwhile, the potential for societal disparity increases as the coastal inhabitants and businesses with fewer resources are forced to move away from an ever-receding shoreline, while those who can afford to stay will rebuild. 
And while Ripple Effect's experience and resources are rooted in a region most urgently experiencing the impacts of climate change, we recognize a growing need for water literacy across the United States. In the coming decades, every community in the country will be impacted by water issues that have been catalyzed or aggravated by climate change, including sea-level rise, drought, and contamination. As the SUSRURI conference exemplifies, addressing these system-level issues sustainably will require cooperation from all of our great institutions, including science, government, design, and, as our organization strongly believes, public schools. It is through teachers and their classrooms that we see an existing channel through which to effect change, one that has the potential to reach further and deeper than almost any other system. Yet the speed with which communities in this region must adapt to climaterelated issues is outpacing the rate at which educational systems are responding to these changes.

Ripple Effect was founded out of a desire to help K-12 public schools move more rapidly toward inquiry-based science education about climate-related water issues that are impacting communities, now. Our hope is that this work will prepare students to address and adapt to the environmental problems they will face as adults, and do so in a way that is grounded in scientific knowledge, creative solution-making, and shared values based in empathy and equity. We are, to a degree, accomplishing this. But any successes we have had and the quickening rise of the sea only drive us to ask, how can we reach more students? How do we transform on a scale that matches the enormity of transformation facing us now? 


\section{About Ripple Effect}

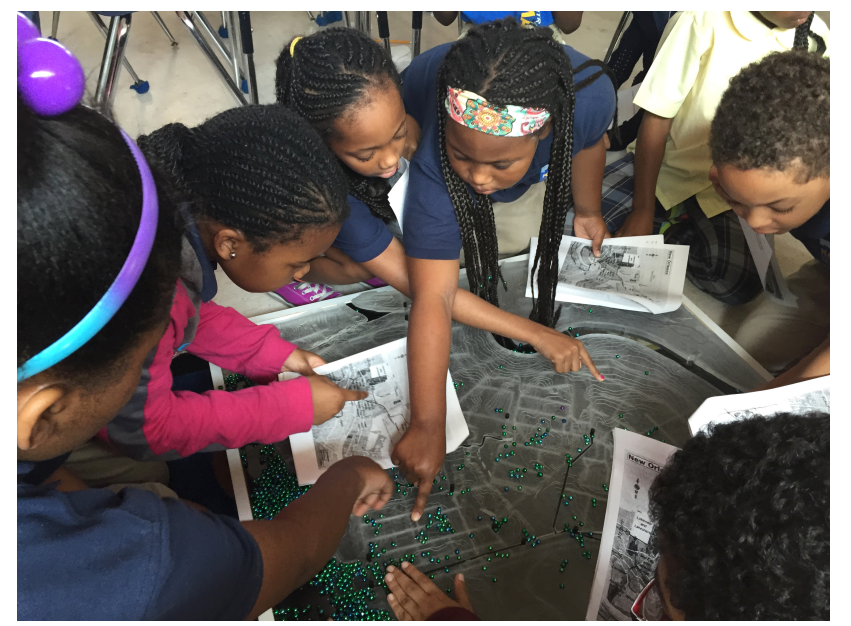

Ripple Effect students using a topographic model and Mardi Gras beads to test predictions and gather evidence about where water
collects during a storm. Topographic model provided by Derek Hoeferlin and his students at Washington University in St. Louis.
The Ripple Effect Water Literacy Project is an education nonprofit that provides standards-aligned, in-school STEM instruction about real people and places impacted by climate change. We work with teachers, scientists, and designers to develop, test, and teach innovative science curriculum in high-need schools, with the explicit aim of improving student achievement and increasing resilience in climate-vulnerable communities. Through education, we believe that our next generation can begin defining a compelling vision for

the future.

Ripple Effect's interdisciplinary science curriculum centers student learning on communities where-due to sea-level rise, stormwater runoff, subsidence, or extreme weather-people are forced to renegotiate their relationship to land and water. This approach necessarily foregrounds issues of historic land ownership, native rights, or personal connection to earth systems and reliance on waterways. Curriculum is produced in collaboration among teachers, scientists, resilience practitioners, water experts, and designers during workshops structured and facilitated by Ripple Effect, then tested in classrooms by Ripple Effect fellows before wider distribution to local teachers.

These educational experiences build toward water literacy. We define water literacy as the systematic collection and sharing of knowledge that all individuals and communities need to successfully adapt to changing environments, investigated primarily through human relationships to water and water systems. Ultimately, we want to foster a new generation of water literate leaders, inculcated not in an ideology or political agenda, but in rigorous scientific inquiry and a concern for the world around them. We want to cultivate leaders in the very same coastal communities that have the least exposure to science and are most likely to be displaced by rising waters in their own lifetimes, so that they will have the knowledge and know-how to tackle the 
challenges that will come with rebuilding in place, retreating inland, or responding in a new way altogether.

\section{New Partnerships in Education}

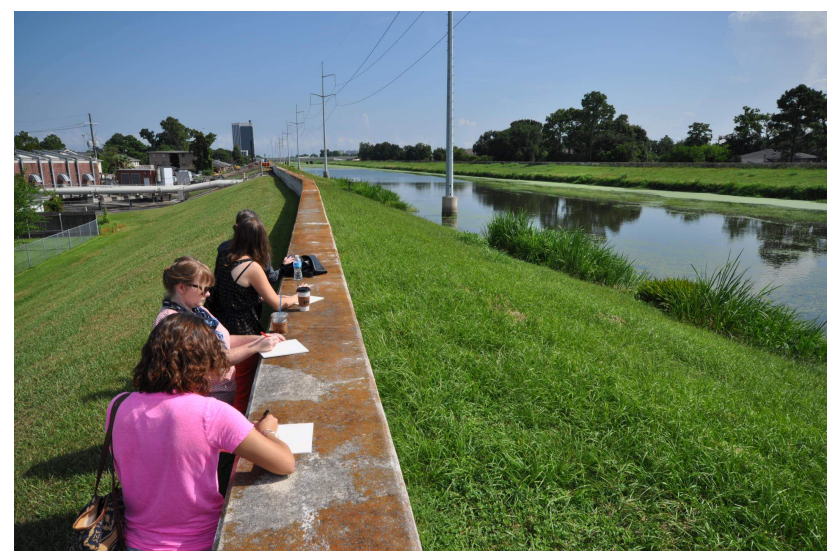

Ripple Effect teachers drawing diagrams and noting their observations of an urban canal, to track the flow of water through the city.
Working outside the boundaries of traditionally defined disciplines has allowed us to make some big-picture observations we plan to use in future transdisciplinary collaborations. In our work to date, we have observed that despite common goals, groups such as New Orleans teachers, coastal scientists, and the local government are unable to communicate effectively with each other. These groups work in adjacent spheres, with little crossover into classrooms.

Experts struggle to translate knowledge gathered in the field to classrooms and the public, and teachers do not know how to access, much less integrate, relevant research into their daily lessons. Yet these connections are vital: in order for teachers to instruct their students on accurate, up-to-date scientific knowledge, teachers must have strong pedagogical and content knowledge, and they must continuously build their skills on both of these fronts in order to effectively bring these ideas to life in the classroom.

The need for bridging this gap is far from limited to Southeast Louisiana. Indeed, direct interaction between environmental scientists and science teachers is not only desired in other states, but it has been recommended by the major national agencies, as well. To cite a few examples: a recent study of scientists at top research universities throughout the United States found that only 3\% collaborated with primary and secondary teachers to help develop practices for teaching science to their students. 3 Similarly, the American Association for the Advancement of Science (AAAS) found that many science teachers' beliefs on climate change do not align with the scientific consensus, noting that "college and university instructors will need help reaching teachers and teachers-in-training who bring diverse political and value commitments to the classroom." $\underline{4}$ The National Science Foundation has reported on the need for scientists to engage in transdisciplinary studies, which include the participation of "social actors"-practitioners in related fields - to establish a new "convergence" 
science, of which SUS is an example. $\underline{5}$ The National Academy of Science (NAS) concluded in its 2014 analysis of field stations that the stations should, among other collaborative activities, build on their site-specific value by actively reaching out to the local population, including citizen scientists, artists, students, and educators. $\underline{6}$ A year later, in its report on Science Teachers' Learning, the NAS also recommended that schools partner with external scientific experts. 7 Yet examples and recommendations of how to execute collaborations of this sort, and meeting academic standards at the same time, are lacking.

Of course, academia's shifting priorities are being driven in the context of rising waters, as human society as a group tries to figure out how to respond systematically to arguably the greatest systemic change on earth. For those already facing hydrological impacts of climate change in their daily lives, deciding what to do can seem like a solitary struggle. Residents and businesses on the Gulf Coast have more familiarity with surviving extreme weather events than most; yet they have little access to the scientific explanations for these hazards or the most sustainable ways to manage them. Shortage of knowledge compounds vulnerability by disenfranchising people from the policy-making that will affect their quality of life. Instead, many perceive their only options as either rebuilding homes that will surely flood again or retreating entirely, moving their homes and livelihoods inland. In New Orleans and other cities with a history of discriminatory zoning laws, neighborhoods which are most vulnerable to water are also predominantly low-income and racially segregated, intensifying other societal fault lines. $\underline{8}$ As a corollary, scientists studying hydrological phenomena do not always have access to the real-world experiences of those living on the coast, thus limiting the impact of their work.

\section{Formal Education}

Meanwhile, another disconnect exists closer to the classroom: the new Next Generation Science Standards (NGSS) for K-12 public education. These state-level standards draw on widely researched and accepted theories of teaching through thematic concepts, emphasizing "figuring out why" over "learning about," $\underline{9}$ and building on the ways individuals make meaning and thus internalize knowledge. $\underline{10}$ The standards raise the bar for rigor in American science education and herald an exciting new era of pedagogy. As happens whenever new standards are introduced, the application of those general guidelines to actual classrooms across the country falls to districts, schools, and, more often than not, individual teachers. Success of NGSS adoption, therefore, relies on the ability of teachers to interpret the standards for their 
students. This in itself would be a formidable challenge, as teachers must re-align or develop wholly new curricula to fit new content and methods, and they often do so on an individual basis, without an organized way to share their work with other teachers, at least not at any significant scale.

But adopting the NGSS also presents an entirely new kind of challenge in, we dare say, the history of teaching. Consider this: we, humans, are living in a time of global change that we have never before had to grapple with. We are learning as we go. Every time predictive climate science models change, they are moving up, not down, the rate of sea level rise. In September 2019, we learned that a third of the United States's bird population disappeared in a single lifetime. Native villages in Alaska have repeatedly run out of fresh drinking water.

Incredibly, the new science standards reflect the current topics of environmental science, including climate change and its related impacts. Based on our analysis, topics related to water literacy, such as climate, weather hazards, water and land interactions, man-made impacts to the environment, and ecosystem destabilization are addressed in 39\% of the Louisiana State Science Standards; water-focused or -related topics on their own account for $16 \%$ of the standards. Teaching to these standards requires teachers to acquire in-depth knowledge of current science and to build advanced skills for leading student-driven science inquiry. Effectively, they are meant to be translating research from the lab to the classroom without losing any meaning in the process. Put another way, the majority of today's public school teachersfrom career pros to novices-are having to teach topics no one has ever taught before, and attempt to equip our youngest generations for a future we cannot take for granted. The sense of urgency that often accompanies discussions of climate change increases the pressure.

How are they doing this? It is certainly true that myriad online resources, offering NGSS-aligned curricula, exist. Yet, a common trend we have noted among teachers is that, after sifting through the myriad, they select (or are given) a curriculum only to alter it beyond recognition as they strive to personalize the content for their students. Moreover, many curricula are stand-alone products, with no additional materials to support teachers' own learning of the new topics or of NGSS pedagogy. Even among those teachers who dedicate their nights and weekends to supplementing their own knowledge, many eventually hit a wall in their search for reliable, current scientific data and research sources. These new data and sources are typically first published for an audience of trained scientists or subject matter experts, not K-12 science teachers, 
who require a different, perhaps more processed, kind of research output, and who process this information yet again for their students' use. This mismatch in the readiness of data perhaps implies that teachers should not be teaching from research that is so fresh; at the same time, with improved training of teachers in scientific knowledge and skills, and with an eye toward translation to K-12 audiences, we could at least start to close the gap between lab and classroom.

Until then, with such barriers to knowledge building, and with limited time and energy, many teachers end up doing exactly what the new standards would deem anathema among students: learning - and then teaching-by rote.

Unsurprisingly, these general challenges are felt even more keenly by new teachers, teachers working in underserved communities, and teachers with limited or no exposure to science at the undergraduate level. Of approximately 211,000 science teachers working nationwide in 2015, only 5\% of elementary school teachers had a bachelor's degree in science, engineering, or science education, compared to $41 \%$ of middle school science teachers and $82 \%$ of high school science teachers. 11 In New Orleans, where Ripple Effect focuses its efforts, 83\% of students attending public school come from economically disadvantaged backgrounds, compared to 51\% nationally. $\underline{12}$ Considering that less experienced teachers are disproportionately assigned to schools where the vast majority of students qualify as low-income, the true brunt of the gap between the theory and practice of NGSS is being borne by children living in poverty. $\underline{13}$ With forty-four states having already adopted the NGSS or its foundational document, the National Research Council's Framework for $\mathrm{K}-12$ Science Education, seventy-one percent of U.S. students and their teachers stand to benefit from these new standards, or struggle in their wake. $\underline{14}$

\section{Moving Forward}

To begin bridging these gaps for K-12 education, Ripple Effect has formed a consortium of university biological field stations, community-based environmental organizations, and environmental educators located in Southeastern Louisiana to codevelop a new initiative, named the Water Literacy Lexicon for Educators.

The Water Literacy Lexicon has three goals:

Goal 1: Communicate a compelling vision for water literacy education that continually bridges the gap between current environmental research, social and historical context, and $\mathrm{K}-12$ education. 
Goal 2: Increase the quantity, quality, and coherence of $\mathrm{K}-12$ teacher and student learning experiences that build deeper understanding of-and engagement in-the most pressing environmental issues of Southeastern Louisiana.

Goal 3: "Mainstream" environmental education, to build a community of empowered water literacy educators and advocates

As a process, the Water Literacy Lexicon is envisioned as a replicable model for convergence that meets the needs of scientific researchers, climate-vulnerable communities, and K-12 educators seeking rigorous and empowering science experiences for their students. As a product, the Water Literacy Lexicon will be an online hub for this convergence to take shape, resulting in a coherent, regional approach to water literacy education.

A completed Water Literacy Lexicon will take shape as a growing database of adaptable teaching tools, media-rich storylines by and about communities facing water challenges, as well as access to sites, individuals, and special environmental education experiences that, together, will form the basis of regional water literacy education.

\section{Audience}

Primarily, the project will serve teachers and students in low-income, climatevulnerable $\mathrm{K}-2$ schools in the Gulf South region.

We want to center our efforts on teachers and students in $\mathrm{K}-12$ public schools serving low-income populations, that is, Title 1 schools. In New Orleans and other cities with a history of discriminatory zoning laws, neighborhoods which are predominantly lowincome also tend to be racially segregated and highly vulnerable to water. Many times, these same conditions converge at the neighborhood school, expressed in a student population that is poor, from racial and ethnic minority groups, and climate-vulnerable.

Focusing on this primary audience does not mean that our work could not later serve teachers and students of other types of schools, both public and private. We see no demographic limit to the benefits of better teacher training. On the contrary, by focusing on the extreme needs of Title 1 schools, we are likely removing the barriers any other teacher probably would face, such as cost, statewide benchmark pressures, teacher experience levels, and diverse needs of students. Unlike many city- and statedriven education initiatives, which look at implementation at the district level or higher, Ripple Effect can build around a subset of teachers of our own choosing, and we see a Title 1 audience as being the most equitable choice. 
As a capacity-building endeavor, the Water Literacy Lexicon will secondarily serve other environmental educators, ecological field station operators, environmental scientists, and district, school-based, or teacher communities in Southeast Louisiana and beyond. Working together, these groups will enhance their access to specific, highdollar NSF and NAS funding, which is designed to support programs or projects that link research, education, and field stations. We will also share program evaluation results with external stakeholders interested in understanding best practices in teacher training and curriculum design.

\section{Interpretive Plan}

To plan and prepare for a future Water Literacy Lexicon, Ripple Effect and other consortium partners in Southeastern Louisiana will begin with an interpretive planning project, to better understand these gaps and how we might build synergy between education and science, policy, and urban sustainability. As part of the interpretive planning process, we hope to investigate the following working hypotheses:

- The national mandates facing climate scientists and science teachers may have enough parallels that these constituents can help each other to meet them. We think the strongest example of this synergy may be embodied in field stations (described below).

- An interactive, web-based platform to train teachers, not only in teaching water literacy to their students, but in internalizing it for themselves may have utility. This digital platform can also extend the reach of our work. We are curious about the potential of an online environment for creating a learning organization made up of teachers, scientists, and other water-focused practitioners. 


\section{Field stations}

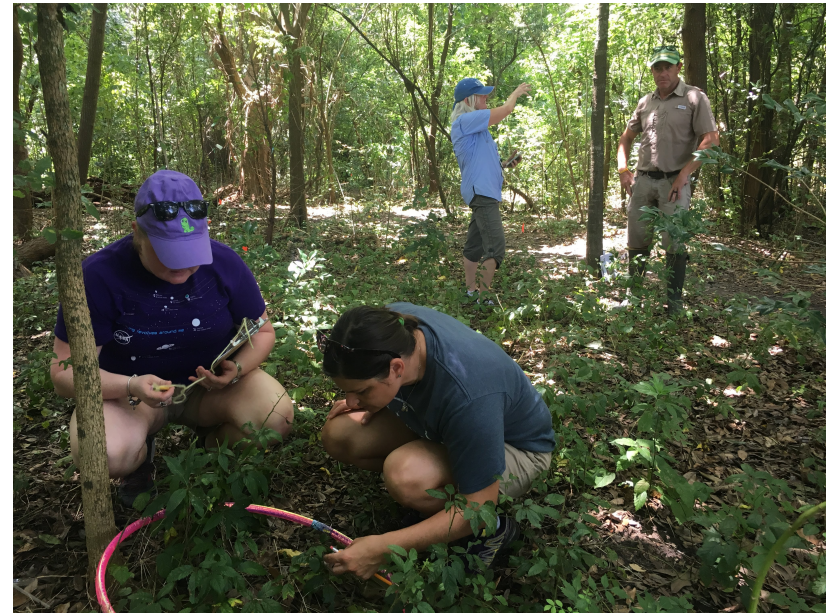

Teachers collecting data on invasive species density in City Park using hula hoops as quadrats. Louisiana Coastal Master Teacher
Fellowship, 2019. Photo by Ripple Effect.

We see potential for the field stations and science teachers of Greater New Orleans to help each other. In their recommendation for more engagement with the local community, the NAS enumerates several ways in which field stations may serve their local educational systems. We have identified three of those recommendations as potential opportunities for, or outcomes of, participation in the water literacy project.

Recommendation 1: Expand programs for active learning, including discovery-based (or inquiry-based) learning, $\underline{15}$ to inspire, strengthen, and retain students in STEM fields

Project tie-in: Field stations' lines of scientific inquiry could provide anchoring phenomena that are requirements for teaching NGSS curricula.

Project tie-in: Field stations could potentially recommend and, with Ripple Effect, design versions of their experiments that are suitable for replication in the classroom and to meet the NGSS.

Recommendation 2: Expand opportunities for integrating the social science and humanities, allowing students and professionals in those fields to learn from, contribute to, and better understand the process of science

Project tie-in: Teachers and students may begin to understand the importance of sharing and communication between scientists, to push research forward and answer the "big questions" in science that a single study could never answer alone.

Project tie-in: Field stations themselves may benefit from being seen through social, historical, or artistic lenses. It could unearth new aspects of stations' heritage and value.

Recommendation 3: Partner with education research, to design programs based on proven methods of how people learn 
Project tie-in: Ripple Effect's teacher training expertise can help field stations augment their teacher programs.

Project tie-in: Focus groups and broader evaluation during interpretive planning could yield specific strategies for improving engagement with students and teachers from Title 1 schools, as well as those learning and working in rural environments.

In this context, it is also worth noting the extensiveness of the field station network. Nine hundred field stations exist around the world; more than seventy of them are located within the Mississippi River Basin. $\underline{16}$ We envision a successful coastal collaboration could later expand to include upriver, inland field stations, in joint projects at the macro level.

\section{Digital technology and interactive tools}

To help teachers learn and teach the more challenging topics of NGSS-climate and water-related sciences-we intend to build an online platform that will provide or connect to the learning experiences needed to achieve personal mastery. We hope the same platform will organize otherwise disconnected teachers into a community that can help itself learn and be readier to respond to future changes of a magnitude similar to the standards.

A digital hub might aggregate strong existing resources. It could be an updatable repository of classroom-ready activities, curricula, field trips, professional development webinars, and community forums for teachers. It could match scientists with teachers, or match one to the other's existing projects. A digital medium could potentially provide user metrics or program evaluation protocols, so that environmental educators, institutions, or individual scientists can analyze the impact of their programs. Most importantly, a shared hub would provide educators with a coherent view of the resources, people, and places available to them as teaching resources.

The planning team may also discuss ways that the digital hub or tool could help meet the existing needs of scientists. Hypothetical examples include: a channel for collecting data from citizen scientists; a resource for incorporating an education component into a grant application; or a platform for surfacing questions popular among users. 


\section{Guiding Questions}

As a result of our participation in the Sustainable Urban Systems conference at Iowa State University, as well as conversations with advisors and fellow consortium members, our team has begun tracking "big" questions and principles that we find important to bear in mind throughout the planning process.

- How can the stories of lived experiences be meaningful yet also maintain scientific objectivity?

- How do we introduce students to the scientific method in the context of climate change, without distraction from climate science's continuous evolution, external social pressures, or politicization?

- Is anything worth saving at risk of being lost in the transition to a convergent science?

- How do we instill stewardship without placing an undue amount of responsibility on young people?

- How might digital tools or information science support and sustain convergence between research and practice?

- How does a convergent project increase in scale, to effectively reach more teachers and students?

Claire Anderson, Executive Director

Laura Koo Nicholas, Lead Content Developer

Ripple Effect, New Orleans, LA

This event is supported by the National Science Foundation, Award \#1929601. Any opinions, findings, and conclusions or recommendations expressed in this material are those of the author(s) and do not necessarily reflect the views of the National Science Foundation.

\section{Footnotes}

1. From Louisiana's Comprehensive Coastal Master Plan: “Under the Low Environmental Scenario, 1,207 square miles could be lost over 50 years. Under the Medium Scenario, 2,254 square miles could be lost. Under the High Scenario, 4,123 square miles could be lost. This predicted land loss is in addition to the nearly 1,900 square miles of land area lost between 1932 and 2010." Coastal Protection and Restoration Authority of Louisiana. 2017. Louisiana's Comprehensive Master Plan for a Sustainable Coast. Coastal Protection and Restoration Authority of Louisiana. 
Baton Rouge, LA. (http://coastal.la.gov/wp-content/uploads/2017/04/2017-CoastalMaster-Plan Web-Book CFinal-with-Effective-Date-06092017.pdf) $\subseteq$ 2.

A few regional examples: Resilient New Orleans; Greater New Orleans Urban Water Plan; Louisiana's Comprehensive Master Plan for a Sustainable Coast; LA SAFE Regional Adaptation Strategy; Resilient Houston: Resilience Assessment.

"Living with Water" is a registered trademark of Waggonner \& Ball Architecture/Environment, first used in the Greater New Orleans Water Plan (https://livingwithwater.com/) $\subseteq$

3. Ecklund EH, James SA, Lincoln AE (2012) How Academic Biologists and Physicists View Science Outreach. PLoS ONE 7(5): e36240. https://doi.org/10.1371/journal.pone.0036240

4. Plutzer E et. al. (2016) Climate Confusion among U.S. Teachers. Science 351 (6274): 664-665. DOI: 10.1126/science.aab3907

5. Advisory Committee for Environmental Research and Education. 2018.

Sustainable Urban Systems: Articulating a Long-Term Convergence Research Agenda. A Report from the NSF Advisory Committee for Environmental Research and Education. Prepared by the Sustainable Urban Systems Subcommittee.https://www.nsf.gov/ere/ereweb/ac-ere/sustainable-urban-systems.pdf

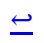

6. National Research Council. 2014. Enhancing the Value and Sustainability of Field Stations and Marine Laboratories in the 21st Century. Washington, DC: The National Academies Press. https://doi.org/10.17226/18806. $ヒ$

7. National Academies of Sciences, Engineering, and Medicine. 2015. Science Teachers' Learning: Enhancing Opportunities, Creating Supportive Contexts. Washington, DC: The National Academies Press. https://doi.org/10.17226/21836. 8. Horowitz A. 2014. Hurricane Betsy and the Politics of Disaster in New Orleans's Lower Ninth Ward, 1965-1967. The Journal of Southern History. 80(4): 893-934. For example, writing about Hurricane Betsy in 1965, Andy Horowitz traces a line of causality stemming from the undesirable, low-lying areas of New Orleans being the only neighborhoods in which Black Americans could buy homes in the postwar era. One of these neighborhoods was the Lower Ninth Ward. Despite poor municipal 
infrastructure, by 1965, it was a solid, working-class community, in which many residents owned their homes. With the construction of the canals and levees in and around this neighborhood, multi-source flooding and storm surge were risks to which residents acquiesced. However, when the unprecedented Betsy made landfall, insensible and unfair recovery policies exacerbated the disastrousness of the event and entrenched this neighborhood in a deep cycle of debt. He shows that the stacked odds had already been in place for a generation in the Lower Ninth Ward by the time Katrina hit. $\_$

9. National Research Council. 2012. A Framework for K-12 Science Education: Practices, Crosscutting Concepts, and Core Ideas. Washington, DC: The National Academies Press. https://doi.org/10.17226/13165. 10. Kucer, S. (2014). Dimensions of Literacy. New York: Routledge, https://doi.org/10.4324/9780203428405 11. National Academies of Sciences, Engineering, and Medicine. 2015. Science Teachers' Learning: Enhancing Opportunities, Creating Supportive Contexts. Washington, DC: The National Academies Press. https://doi.org/10.17226/21836. 12. Babineau K, Hand D, Rossmeier V. 2018. The State of Public Education in New Orleans 2018. New Orleans: Cowen Institute, Tulane University. http://www.thecoweninstitute.com.php56-17.dfw31.websitetestlink.com/uploads/SPENO 2018 Final - Double Page Spread1524079581.pdf. As detailed in the report, in schools that were part of the Recovery School District-which serves a student population of over $80 \%$ low-income and minority students - over $60 \%$ of teachers have fewer than five years of teaching experience and over $80 \%$ of teachers had fewer than 10 years of experience. This reflects national trends. $\uplus$

13. National Academies of Sciences, Engineering, and Medicine. 2015. Science Teachers' Learning. According to this report, "in schools with the highest poverty quartile, 45 percent of science teachers have 5 or fewer years of science teaching expertise, compared with just 25 percent of those in the lowest poverty quartile." $ヒ$ 14. This NGSS website tracks which U.S. states have adopted the new standards or framework: https://ngss.nsta.org/About.aspx. Information about the NRC's Framework can be found here: https://www.nextgenscience.org/framework-k-12$\underline{\text { science-education. }}$. 
15. National Research Council. 2014. Enhancing the Value and Sustainability of Field Stations and Marine Laboratories. From the report, discovery-based learning "requires students to pose their own questions and develop hypotheses and to design experiments to address their questions...a type of active learning, a student-centered approach to instruction, which requires students to engage in meaningful learning activities." $\triangleq$

16. National Research Council. 2014. Enhancing the Value and Sustainability of Field Stations and Marine Laboratories. $€$ 